\title{
Outdoor thermal environment of a traditional settlement with a group of wooden storehouses in summer daytime at Tsushima Island, Japan
}

\author{
Tsuyoshi Hashimoto ${ }^{1)}$ and Shinichi Watanabe ${ }^{2)}$ \\ 1) Faculty of Art and Design, University of Tsukuba, Ibaraki, 305-8574, Japan \\ Tel: +81-029-853-2710 \\ E-mail:go@geijutsu.tsukuba.ac.jp \\ 2) School of Engineering, Daido University, 457-8532, Japan \\ Tel: +81-052-612-5953 \\ E-mail:nabeshin@daido-it.ac.jp
}

(received on 28th July, 2020, accepted on 14th September, 2020)

\begin{abstract}
Traditional settlements have been formed by adapting to local climate and natural features. This study aims to clarify the climatic characteristics of a settlement with a group of wooden storehouses in summer daytime from the viewpoint of environmental design. Waniura settlement in Tsushima Island, Japan was selected as the observation site of this study. The largest group of wooden storehouses in Tsushima Island is in Waniura settlement, and it is in the north of the settlement. About 150 storehouses are located near the port. The microclimate observations in the settlement and heat parameters measurements, including UV intensities at three representative points, were carried out in the summer of 2019. The wind direction in the northern part of the settlement had a different trend than that in the sky. The wind directions in Waniura settlement is affected by the topography when the wind in the sky blows in different directions from the valley line in the settlement. The layout of storehouses affects the wind environment of the group of wooden storehouses and the wind reducing effect appears when the wind blows orthogonally to the parallel storehouses. At the shaded path (point-C) on $1,000 \mathrm{~W} / \mathrm{m}^{2}$ global solar radiation, the MRT reduction was $-25.7^{\circ} \mathrm{C}$. The reason the MRT at the shaded path dropped significantly was that the storehouses built close to each other blocked the solar radiation on the shaded path significantly. Furthermore, less solar radiation on the shaded path might contribute to maintaining the low surface temperatures of the pathway and the storehouses. At the shaded path on $1,000 \mathrm{~W} / \mathrm{m}^{2}$ global solar radiation, the UTCl reduction was $-4.4^{\circ} \mathrm{C}$. This result emphasizes the importance of providing shade from buildings or other means and directing wind into those spaces to improve the outdoor thermal environment. At the shaded path in the group of wooden storehouses on $1000 \mathrm{~W} / \mathrm{m}^{2}$ global solar radiation, the UV Index reduction was -5.4 . This large UV Index reduction at the shaded path can be because the storehouses were built close to each other, thus blocking most direct and diffuse components of UV radiation. It has become clear that a heat island appears in the centre of the settlement with a population of about 200 people in the daytime on a clear summer day. In contrast, the heat island did not appear in the group of wooden storehouses, despite the dense construction of storehouses. This is probably because the storehouse is a low-rise wooden building with low heat capacity and because there is no energy consumption or waste heat there. It is evident that the cooling effect of the group of storehouses on the radiant environment, thermal environment and UV environment appears in the summer daytime. Based on the results of the field observations, it has been empirically shown that it is an effective environmental design method for mitigating the thermal environment in the summer daytime by composing a group of low-rise wooden buildings is concerned with taking into account their ventilation.
\end{abstract}

Keywords: microclimate, MRT (Mean Radiant Temperature), UTCI (Universal Thermal Climate Index), UV (ultraviolet) Index, group of wooden storehouses 


\section{Introduction}

Traditional settlements have been formed by adapting to local climate and natural features. There is much to be learned from the design methods of such traditional settlements in considering a low environmental impact life that is suitable for the local climate. There are many studies on the local environmental design of traditional settlements in various regions. Focused on studies on the relationship between environment and settlement design in East Asia, Tao et al. (2017) described the influences of the natural environment on spatial patterns of traditional settlement in the Dabu region, China. Chu et al. (2017) explored the design philosophy of ancient Chinese people through analysis of wind environment using CFD. Horikoshi et al. (1990) studied changes in the landscape and dwellings with windbreaks along the coast of Enshu, Japan. Sekiguti (1950) reported the relationship between the prevailing wind direction and the facing direction of rural houses in Akaho area, Nagano Prefecture, Japan. Natsume (2019) focused on the woodland in Kichijoji village and wind condition was analysed based on a $3 \mathrm{D}$ reconstruction of the landscapes in early modern Japan.

Although a large number of studies were made of the relationship between environment and settlement design, there are ever so many more other interesting regional landscape of settlements in East Asia. As one such example, this study focused on the group of wooden storehouses. Although the group of wooden storehouses are generally interpreted as a fire protection design, few studies have clarified the thermal environment formed in the group of wooden storehouses and the relationship between the local climatic environment and the layout of the group of wooden storehouses. We focused on the group of wooden storehouses called "Koya-Yashiki" in Tsushima Island, Japan. Hashimoto et al. (2019) focused on Kuneinaka settlement in Tsushima Island and studied the relationship between the layout pattern of stone roof storehouses and the local wind climate in winter. This study aimed to clarify the climatic characteristic of a settlement with a group of wooden storehouses in the summer daytime from the viewpoint of environmental design.

\section{Method}

Waniura settlement in Tsushima Island, Japan, was selected as the observation site of this study. Figure
1 shows the location of Tsushima Island and Waniura settlement. Tsushima Island is in the west of Japan, between Fukuoka City and South Korea. Waniura settlement is in the north of Tsushima Island. According to the Basic Resident Register, as of the end of July 2019, Waniura settlement had a population of 207 people and 116 households.

Table 1 shows the timetable of the microclimate observations and detailed measurements in the settlement. In this study, microclimate observations over the settlement and detailed measurements of thermal parameters and ultraviolet intensities at three typical points were carried out in summer. The microclimate observations were carried out from the 21 st through 23 rd of July 2019. The measurement periods of detailed measurements were 10:40-17:00 on July 22nd and 10:30-13:00 on July 23rd in 2019. Figure 2 shows the observation site and measurement points. In Tsushima Island, groups of wooden storehouses are one of the most important local climatic landscape. The largest group of wooden storehouses in Tsushima Island is in Waniura settlement (Kobayashi et al., 2007), and it is in the north of the settlement. Figure 3 shows a group of wooden storehouses in Waniura settlement. About 150 storehouses are built near the port. Fishing equipment, household goods, and grain were stored in storehouses (Kobayashi et al., 2007).

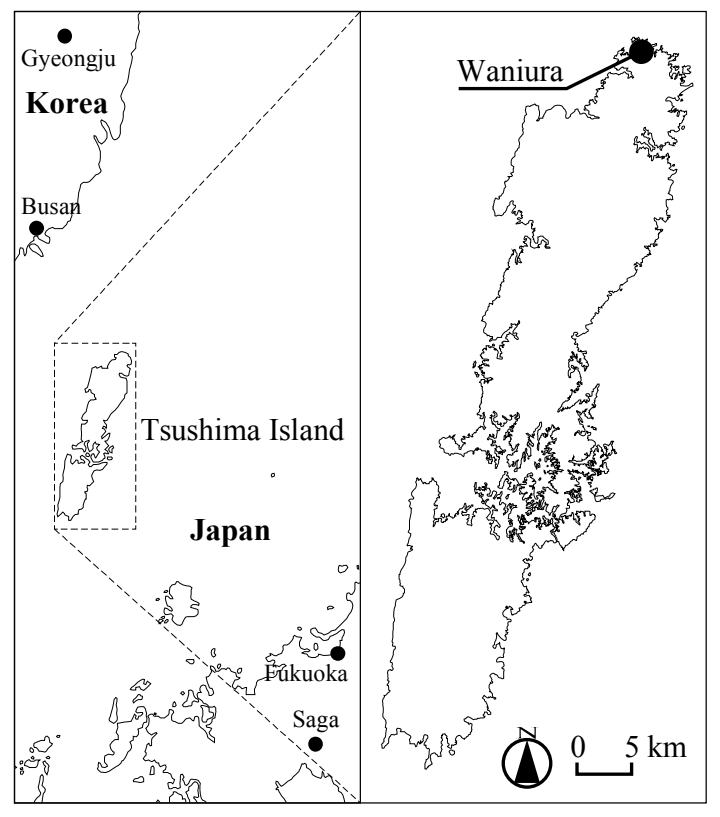

Fig. 1 Location of Tsushima Island and Waniura settlement

Table 1 Timetable of the microclimate observations and detailed measurements

\begin{tabular}{ccc}
\hline Observation days & The start time of moving observation & The measurement period of detailed measurement \\
\hline \hline July 21,2019 & $15: 00,17: 00$ & - \\
July 22,2019 & $5: 30,10: 00,13: 00,14: 00,15: 00,17: 00$ & $10: 40-17: 00$ \\
July 23,2019 & $11: 00,12: 00,13: 00$ & $10: 30-13: 00$ \\
\hline
\end{tabular}




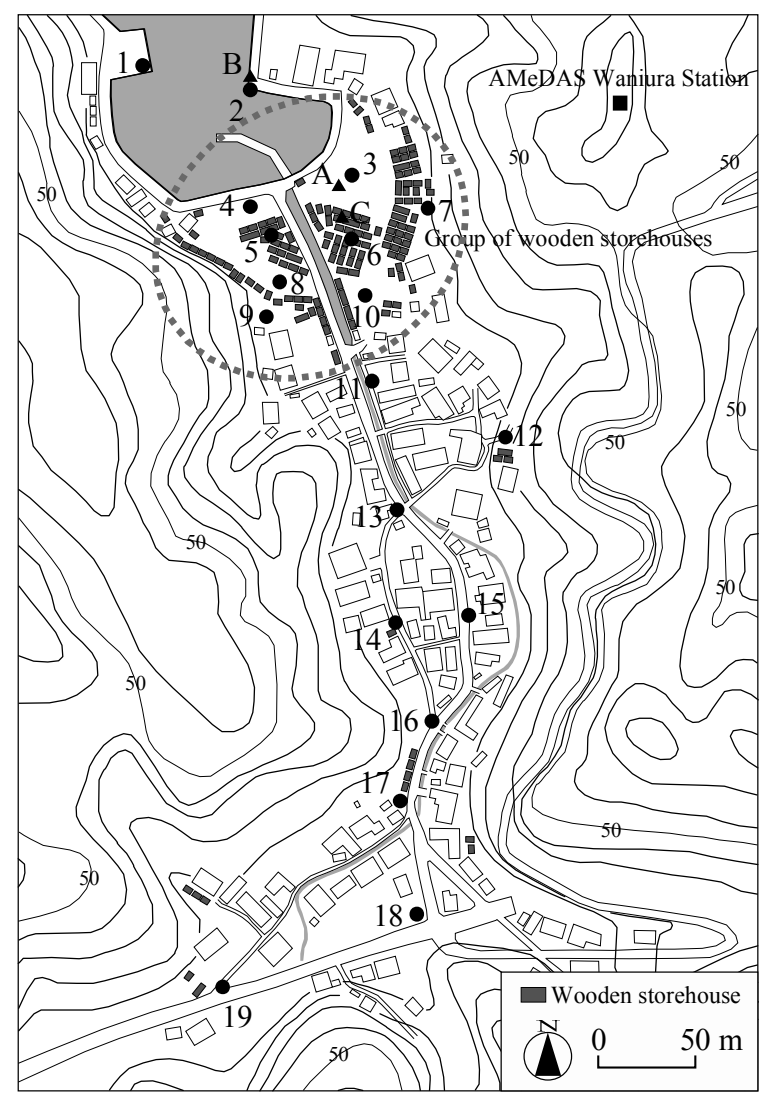

Fig. 2 Observation site and measurement points

The method of microclimate observation in the settlement is described below. Air temperature, humidity, wind direction and velocity were observed at each observation point in Waniura settlement. Air temperature and humidity were observed at 0.9 meters above the ground using an Assmann's ventilated aspiration psychrometer (54-EC, Ota Keiki Seisakusho). Wind direction and velocity were observed at 1.3 meters above the ground using a Byram anemometer with wind vanes (Ando Keiki). These climatic conditions were measured at one fixed observation point and 21 mobile observation points. The fixed point was set up at observation point 1 , at the port. Solar radiation was observed on the ground at the fixed point using a pyranometer (EKO Instruments, MS-802). Climatic conditions were observed mainly in the daytime. On July 22nd, climatic conditions were also observed early in the morning. Observation points 5 and 6 were in a group of wooden storehouses. Observation points 3, 4, 8 and 10 were at the open space, the drying place called "Be-Doko". A time correction was applied to the air temperature and humidity data at the mobile observations based on the data at the fixed observation. It took about 40-50 minutes to perform a series of microclimate observations.

Many studies have been conducted to clarify outdoor thermal comfort in various climatic regions using several thermal indices, including the

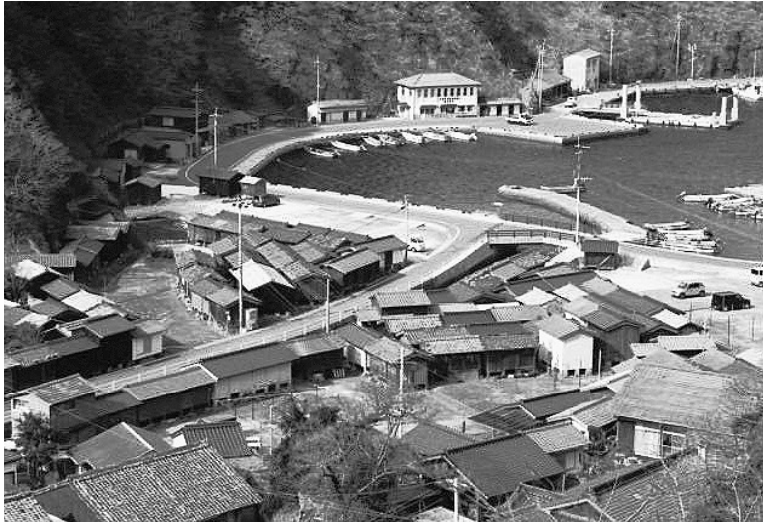

Fig. 3 Group of wooden storehouses in Waniura settlement

physiological equivalent temperature (PET) (Höeppe, 1999), the outdoor standard effective temperature (OUT_SET*) (Pickup and de Dear, 2000), and the universal effective temperature (ETU) (Nagano and Horikoshi, 2011). Generally, six thermal parameters (air temperature, humidity, air velocity, mean radiant temperature, clo-value, and metabolic rate) are required to calculate index values. The universal thermal climate index (UTCI) (Jendritzky et al., 2012), however, can calculate index values with four environmental variables (air temperature, humidity, air velocity, and mean radiant temperature), because metabolic rate is assumed to be walking at $4 \mathrm{~km} / \mathrm{h}\left(2.3 \mathrm{met}=135 \mathrm{~W} / \mathrm{m}^{2}\right)$ and clovalue is estimated by the clothing model incorporated in the UTCI calculation (Havenith et al., 2012). In this study, the UTCI model was adopted for evaluating outdoor thermal comfort. In addition to the thermal environment, UV intensity was also measured in the settlement. WHO et al. (2002) warn that excessive UV exposure causes health hazards. To evaluate the comprehensive environment of the settlement from the viewpoint of safety and health, it is necessary to consider the UV environment as well as the thermal environment. The method of detailed measurements in the settlement is described below. Detailed measurements of thermal parameters and UV intensities were performed at three measurement points in the settlement; A: Open space, B: Open seaside, C: Shaded path between wooden storehouses, as shown in Figure 2 . The measurement periods were 10:40-17:00 on July 22nd and 10:30-13:00 on July 23rd, 2019, as shown in Table 1. Table 2 shows the views of three measured points and corresponding Sky View Factors (SVF). Measurement points A: Open space and B: Open seaside had SVFs of 82.5 and $88.0 \%$, respectively, and were open to the sky. Measurement point C: Shaded path with a SVF of $34.3 \%$ was selected in the narrow path between wooden storehouses. Table 3 shows the measured parameters and instruments, as well as measured heights and intervals.

In this study, the UTCI model was adopted for 
Table 2 Measured points and corresponding Sky view factors

\begin{tabular}{|c|c|c|c|}
\hline Measured point & $\begin{array}{c}\text { A: Open space-the } \\
\text { drying space }\end{array}$ & $\begin{array}{c}\text { C: Shaded path in the } \\
\text { group of wooden } \\
\text { storehouses }\end{array}$ \\
\hline View of the measured point & B: Open seaside & \\
\hline Sky view factor [\%] & & \\
\hline
\end{tabular}

Table 3 Measured parameters and instruments

\begin{tabular}{|c|c|c|c|}
\hline Measured parameter & Measured instrument & Measured height & Measured interval \\
\hline $\begin{array}{l}\text { Short- and long-wave radiation flux } \\
\text { (downward and upward) }\left(\mathrm{W} / \mathrm{m}^{2}\right)\end{array}$ & $\begin{array}{l}\text { Four-component Net Radiometer } \\
\text { (NR01, Hukseflux) }\end{array}$ & $\mathrm{GL}+1.1 \mathrm{~m}$ & $10 \mathrm{sec}$. \\
\hline Wind velocity and direction $(\mathrm{m} / \mathrm{s})$ & $\begin{array}{l}\text { Ultrasonic Anemoneter } \\
\text { (ATMOS-22, METER) }\end{array}$ & $\mathrm{GL}+1.3 \mathrm{~m}$ & $1 \mathrm{~min}$. \\
\hline $\begin{array}{c}\text { Air temperature }\left({ }^{\circ} \mathrm{C}\right) \\
\text { Relative humidity }(\%)\end{array}$ & $\begin{array}{l}\text { Temperature and Humidity Sensor } \\
\text { (VP-4, METER) }\end{array}$ & $\mathrm{GL}+1.1 \mathrm{~m}$ & $1 \mathrm{~min}$. \\
\hline UV Index & Vantage Pro UV Sensor (6490, Davis) & $\mathrm{GL}+1.1 \mathrm{~m}$ & $5 \mathrm{sec}$. \\
\hline
\end{tabular}

evaluating outdoor thermal comfort, as mentioned above. This model requires four environmental variables (air temperature, humidity, air velocity and mean radiant temperature) to calculate the index values. Measured air temperature and relative humidity were used in the calculation. As the UTCI model requires the wind velocity at 10 meters above the ground, the wind velocity data measured at 1.3 meters high were converted to that at 10 meters using the equation by Bröde et al. (2012). The mean radiant temperature (MRT) was calculated by the calculation method proposed by Watanabe and Horikoshi (2012) using the measured upward and downward long- and short-wave radiation fluxes. In the MRT calculation, the solar radiation absorptance of the clothed human body was set at 0.66 for the summer season, according to Watanabe et al. (2013). In addition, the human projection area factor due to direct solar radiation was applied to the equation for walking (Park and Tuller, 2011). The effective radiation area factor was set to be 0.91 for a clothed and standing human body (Horikoshi et al., 1990).

AMeDAS Waniura Station is located to the northeast of Waniura settlement. AMeDAS Waniura Station is 63 meters above sea level and the anemometer is 8.0 meters high above the ground.

\section{Results}

\subsection{Weather conditions on observation days}

Figure 4 shows changes in air temperature and sunshine duration at AMeDAS Waniura Station. Table 4 shows the results of air temperature, water vapour pressure, relative humidity, wind velocity and solar radiation at each mobile observation. On July 21st, it was generally sunny from 15:00 to 18:00. At AMeDAS Waniura Station, the daily maximum temperature was $27.2^{\circ} \mathrm{C}$ at $16: 00$, and air temperature in the settlement was higher than that at the observatory. On July 22nd, it was generally cloudy with occasional sunshine. At AMeDAS Waniura Station, the daily maximum temperature was $27.4^{\circ} \mathrm{C}$ at $15: 00$. It was sunny during the mobile observation at 15:00 and the maximum air temperature in the settlement was $31.0^{\circ} \mathrm{C}$ at that time. On July 23rd, it was sunny from about 10:00 to $12: 00$ and then cloudy. It was sunny during the mobile observation at 11:00. At that time, the maximum air temperature in the settlement was $31.4^{\circ} \mathrm{C}$ and the wind was relatively strong, with a maximum wind velocity of $5.6 \mathrm{~m} / \mathrm{s}$.

At AMeDAS Waniura Station, the normal daily maximum temperature in July is $27.0{ }^{\circ} \mathrm{C}$ and that in August is $28.8^{\circ} \mathrm{C}$. The observation period was probably during summer climatic conditions. 


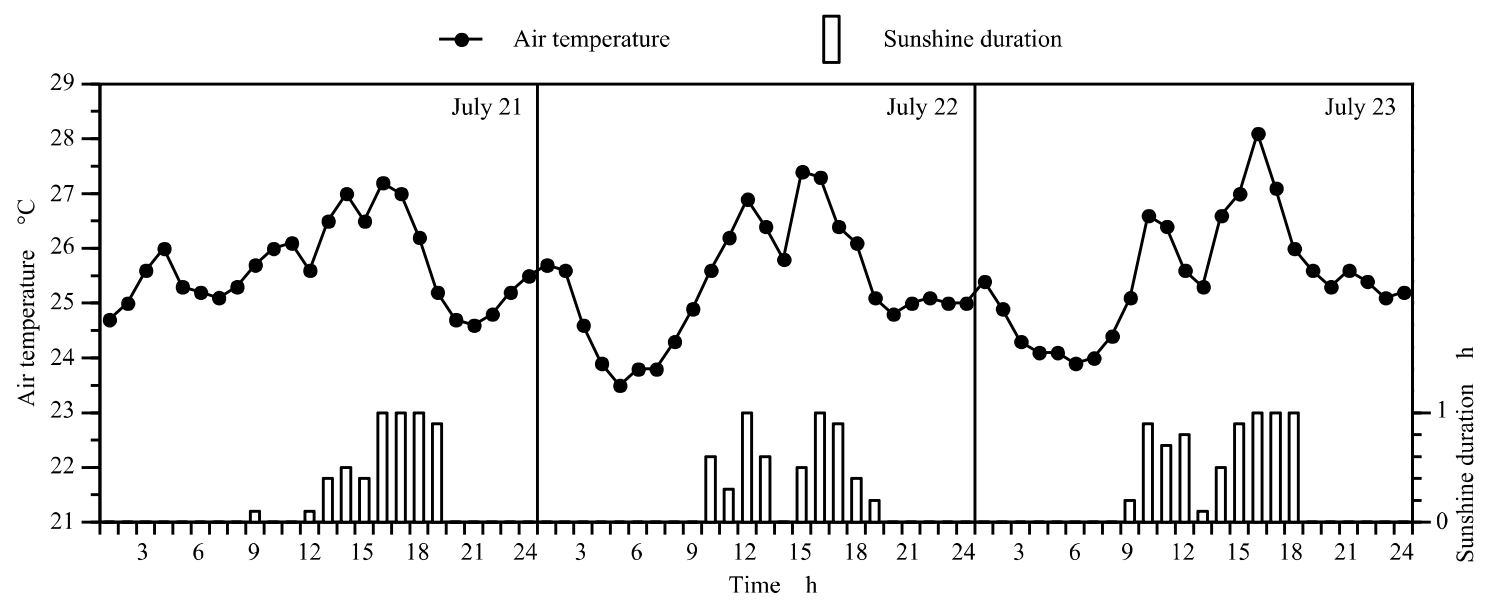

Fig. 4 Changes in air temperature and sunshine duration at AMeDAS Waniura Station

Table 4 Results of air temperature, water vapor pressure, relative humidity, wind velocity and solar radiation in each mobile observation

\begin{tabular}{|c|c|c|c|c|c|c|c|c|c|c|c|c|c|c|c|}
\hline \multirow{2}{*}{\multicolumn{2}{|c|}{$\begin{array}{l}\text { Observation } \\
\text { days and } \\
\text { times }\end{array}$}} & \multicolumn{3}{|c|}{ Air temperature ${ }^{\circ} \mathrm{C}$} & \multicolumn{3}{|c|}{$\begin{array}{l}\text { Water vapour } \\
\text { pressure } \mathrm{hPa}\end{array}$} & \multicolumn{3}{|c|}{ Relative humidity \% } & \multicolumn{3}{|c|}{ Wind velocity $\mathrm{m} / \mathrm{s}$} & \multirow{3}{*}{$\begin{array}{c}\begin{array}{c}\text { Solar } \\
\text { radiation } \\
\mathrm{W} / \mathrm{m}^{2}\end{array} \\
550\end{array}$} & \multirow{3}{*}{$\begin{array}{c}\text { Weather } \\
\text { Sunny }\end{array}$} \\
\hline & & \multirow{2}{*}{$\begin{array}{c}\text { Mean } \\
28.6\end{array}$} & \multirow{2}{*}{$\begin{array}{c}\text { Max. } \\
29.3\end{array}$} & \multirow{2}{*}{$\begin{array}{c}\text { Min. } \\
27.4\end{array}$} & \multirow{2}{*}{$\begin{array}{c}\text { Mean } \\
28.7\end{array}$} & \multirow{2}{*}{$\begin{array}{c}\text { Max. } \\
30.4\end{array}$} & \multirow{2}{*}{$\frac{\text { Min. }}{27.9}$} & \multirow{2}{*}{$\begin{array}{c}\text { Mean } \\
80\end{array}$} & \multirow{2}{*}{$\frac{\text { Max. }}{85}$} & \multirow{2}{*}{$\begin{array}{c}\text { Min. } \\
77\end{array}$} & \multirow{2}{*}{$\begin{array}{c}\text { Mean } \\
1.4\end{array}$} & \multirow{2}{*}{$\frac{\text { Max. }}{2.5}$} & \multirow{2}{*}{ Min. } & & \\
\hline July & $15: 00$ & & & & & & & & & & & & & & \\
\hline 21 & $17: 00$ & 28.4 & 29.6 & 27.7 & 28.4 & 29.2 & 27.7 & 80 & 83 & 76 & 1.3 & 3.7 & 0.0 & 79 & Sunny \\
\hline July & $5: 30$ & 24.4 & 24.6 & 24.1 & 29.4 & 29.7 & 29.1 & 97 & 98 & 96 & 0.5 & 1.8 & 0.0 & 4 & Cloudy \\
\hline \multirow[t]{5}{*}{22} & $10: 00$ & 27.2 & 27.4 & 26.8 & 30.9 & 31.6 & 30.5 & 89 & 91 & 88 & 1.2 & 3.3 & 0.2 & 270 & Cloudy \\
\hline & $13: 00$ & 28.2 & 29.5 & 27.2 & 30.3 & 31.3 & 29.3 & 84 & 87 & 81 & 1.1 & 2.3 & 0.1 & 345 & Cloudy \\
\hline & $14: 00$ & 27.5 & 28.1 & 26.3 & 29.8 & 31.0 & 29.1 & 86 & 90 & 83 & 1.5 & 3.3 & 0.1 & 351 & Cloudy \\
\hline & $15: 00$ & 29.6 & 31.0 & 28.7 & 29.9 & 31.4 & 29.0 & 79 & 84 & 75 & 1.4 & 3.2 & 0.0 & 736 & Sunny \\
\hline & $17: 00$ & 27.8 & 28.3 & 27.3 & 30.0 & 31.3 & 29.4 & 85 & 87 & 83 & 1.7 & 3.3 & 0.4 & 157 & Cloudy \\
\hline July & $11: 00$ & 29.3 & 31.4 & 28.0 & 30.8 & 33.9 & 25.9 & 82 & 91 & 73 & 1.7 & 5.6 & 0.0 & 1022 & Sunny \\
\hline \multirow[t]{2}{*}{23} & $12: 00$ & 28.1 & 29.3 & 27.0 & 30.3 & 31.7 & 29.3 & 85 & 89 & 80 & 1.3 & 3.2 & 0.1 & 675 & Cloudy \\
\hline & $13: 00$ & 27.7 & 29.0 & 26.5 & 30.0 & 31.6 & 29.0 & 85 & 89 & 80 & 1.5 & 3.1 & 0.2 & 580 & Cloudy \\
\hline
\end{tabular}

\subsection{Results of microclimate observations in the settlement}

Figure 5 shows the distribution of air temperature, wind scale, and wind direction at 15:00 on July 22nd, 2019 as an example of mobile observation under a clear sky. At AMeDAS Waniura Station, the relatively strong, scale 4 westerly wind was observed and the air temperature was $27.4{ }^{\circ} \mathrm{C}$. In the northern part of the settlement, the wind directions were different from that at the observatory, and the winds were blowing from the southeast. In the southern part of the settlement, the westerly winds were blowing as at the observatory and scale 1 to scale 2 winds were blowing into the settlement as the wind direction changed from west to south along the valley line. Focusing on the area near the harbour in the northern part of the settlement, a relatively low-temperature area of $29.0^{\circ} \mathrm{C}$ was observed in the area of the group of wooden storehouses and a relatively high-temperature area above $29.5{ }^{\circ} \mathrm{C}$ was observed in the open space, in the drying place called "Be-Doko". The wind was calm at the observation point in the western area of the group of wooden storehouses. In the eastern area of the group of wooden storehouses, scale 2 wind was blowing along the arrangement of wooden storehouses. A heat island was observed in the centre of the settlement.

Figure 6 shows the distribution of air temperature, wind scale and wind direction at 11:00 on July 23rd, 2019 as an example of mobile observation on a windy day under a clear sky. At AMeDAS Waniura Station, a relatively strong, scale 4 westerly wind was observed and the air temperature was $26.4{ }^{\circ} \mathrm{C}$. In the northern part of the settlement, the wind directions were different from that at the observatory and the winds were blowing from between north and west-northwest. In the southern part of the settlement, scale 2 westerly winds were blowing as at the observatory. Focusing on the 


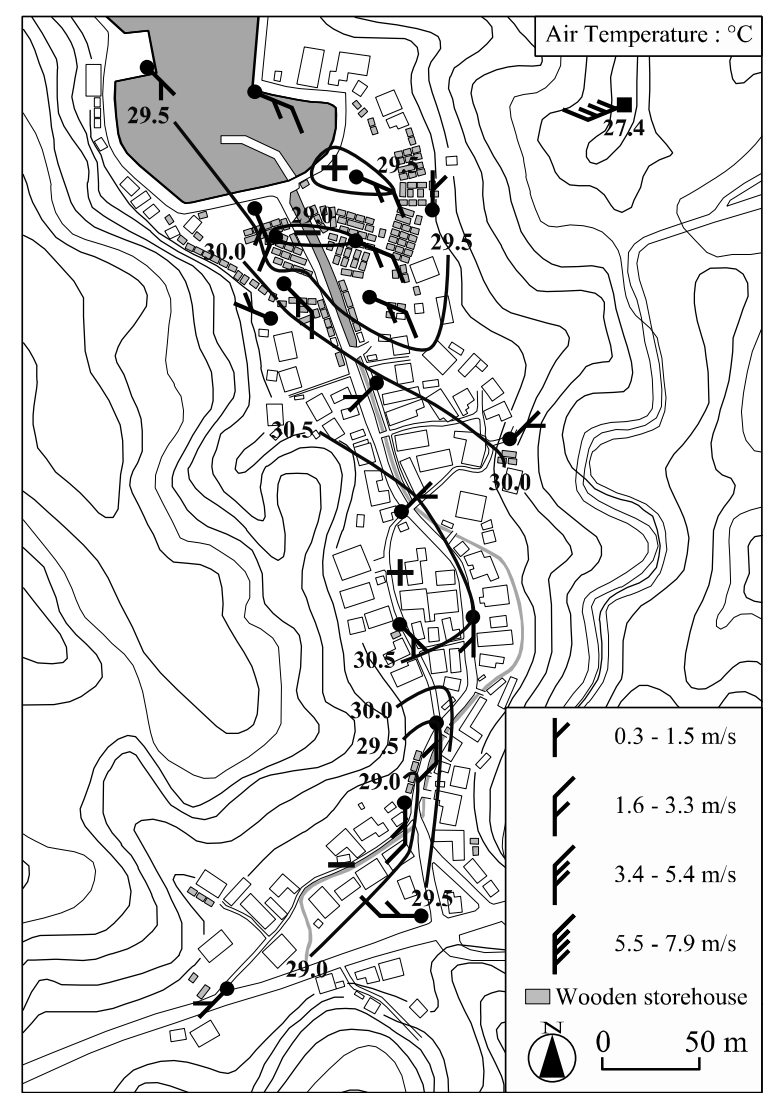

Fig. 5 Distribution of air temperature, wind scale and wind direction at 15:00 on July 22nd, 2019

area near the harbour in the northern part of the settlement, the air temperature was lower the closer to the sea. Winds were calm at observation points in the group of wooden storehouses. A heat island was observed in the centre of the settlement.

Figure 7 shows the distribution of air temperature, wind scale and wind direction at 14:00 on July 22nd, 2019 as an example of mobile observation under a cloudy sky. At AMeDAS Waniura Station, the relatively strong, scale 4 westerly wind was observed and the air temperature was $25.8^{\circ} \mathrm{C}$. In the northern part of the settlement, the wind directions were different from that at the observatory and the winds were blowing from the southeast. A relatively low-temperature area of less than or equal to $27.0{ }^{\circ} \mathrm{C}$ was observed in the eastern area of the group of wooden storehouses. In the eastern area of the group of wooden storehouses, scale 2 wind was blowing along the arrangement of wooden storehouses. Although a heat island was observed in the centre of the settlement, it was not as clear as the result under the clear sky.

Figure 8 shows the distribution of air temperature, wind scale and wind direction at 5:30 on July 22nd, 2019 as an example of mobile observation early in the morning. At AMeDAS Waniura Station, scale 2 westerly wind was observed, and the air temperature was $23.8^{\circ} \mathrm{C}$. The wind directions were different from that at

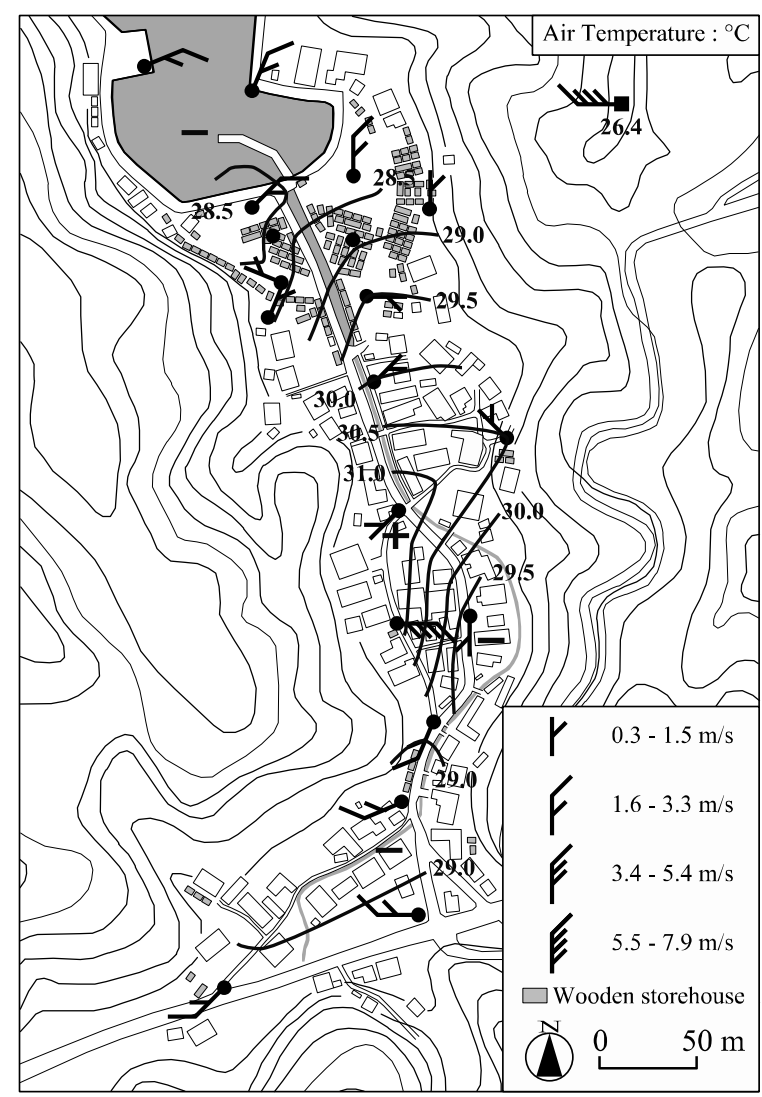

Fig. 6 Distribution of air temperature, wind scale and wind direction at 11:00 on July 23rd, 2019

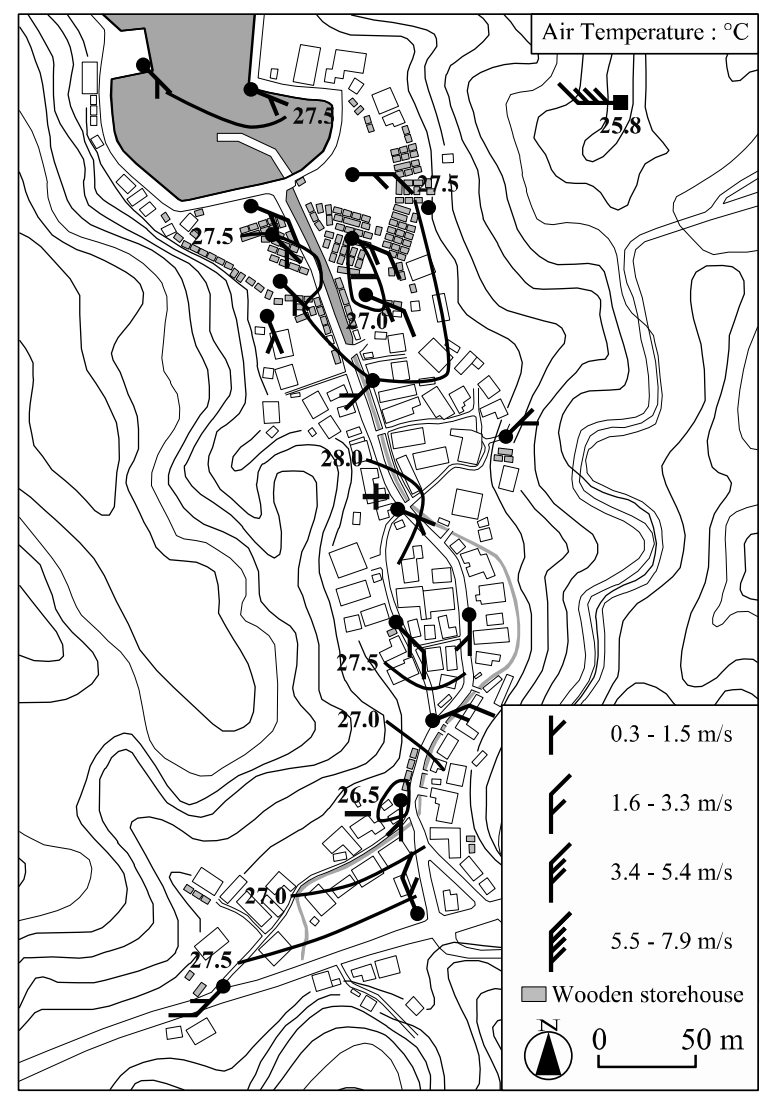

Fig. 7 Distribution of air temperature, wind scale and wind direction at 14:00 on July 22nd, 2019 
the observatory, and wind blowing from between northeast and southeast was observed at various locations in the observation area. The wind was blowing at less than or equal to scale 1 , except at a few observation points. In and around the western area of the group of wooden storehouses, in particular, the wind was calm. The air temperature difference in the observation site was minor compared with the results in the daytime. A weak heat island appeared in the centre of the settlement. A relatively high-temperature area was also formed near the sea in the northern part of the settlement.

\subsection{Results of measurements at three representative points}

Figure 9 shows the changes in air temperature at three representative points on July 22nd and 23rd, 2019. On July 22nd, there was no clear difference in air temperatures at the three points. The average air temperatures were $28.7^{\circ} \mathrm{C}$ at the drying place called "BeDoko" (point-A), $28.6^{\circ} \mathrm{C}$ at the open seaside (point-B) and $28.4{ }^{\circ} \mathrm{C}$ at the shaded path in the group of wooden storehouses (point-C). On July 23rd, the air temperature at the open seaside (point-B) was relatively low and that at the shaded path (point-C) was relatively high compared to that at open space (point-A). The average air temperatures were $28.4,27.6$ and $28.7^{\circ} \mathrm{C}$ at the open space (point-A), open seaside (point-B), and the shaded path (point-C), respectively. Average air temperature at the shaded path (point-C) was $1.1^{\circ} \mathrm{C}$ higher than that at the open seaside (point-B).

On July 22nd, the average relative humidities were 78.1, 78.5 and 78.4\% at the open space (point-A), the open seaside (point-B) and the shaded path (pointC), respectively. There was no difference in relative humidity between the three representative points on that day. In contrast, on July 23rd, the average relative humidities were $79.7,83.1$ and $77.7 \%$ at the open space (point-A), the open seaside (point-B) and the shaded path (point-C), respectively. The relative humidity at the open seaside (point-B) was slightly higher than the other two measured points.

Figure 10 shows the changes in wind velocities at three representative measurement points on July 22nd and 23rd, 2019. On July 22nd, a relatively strong wind was blowing at the open space (point-A) and a relatively weak wind was blowing at the shaded path in the group of wooden storehouses (point-C). The average wind velocities were $2.6,1.7$ and $1.5 \mathrm{~m} / \mathrm{s}$ at the open space (point-A), the open seaside (point-B) and the shaded path (point-C), respectively. Meanwhile, on July 23rd, a relatively strong wind was blowing at the open seaside (point-B), and a relatively weak wind was blowing at the shaded path (point-C). The average wind velocities were $1.7,3.0$ and $0.8 \mathrm{~m} / \mathrm{s}$ at the open space (point-A), open seaside (point-B) and the shaded path (point-C), respectively. From these results, it can be

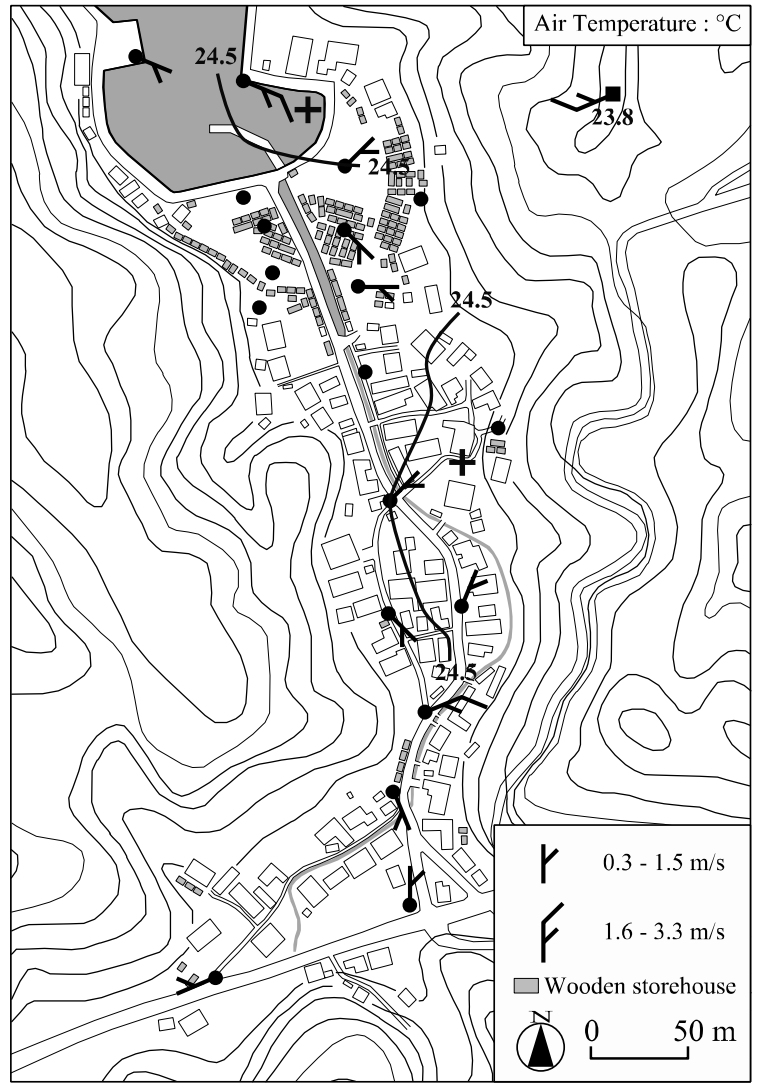

Fig. 8 Distribution of air temperature, wind scale and wind direction at 5:30 on July 22nd, 2019

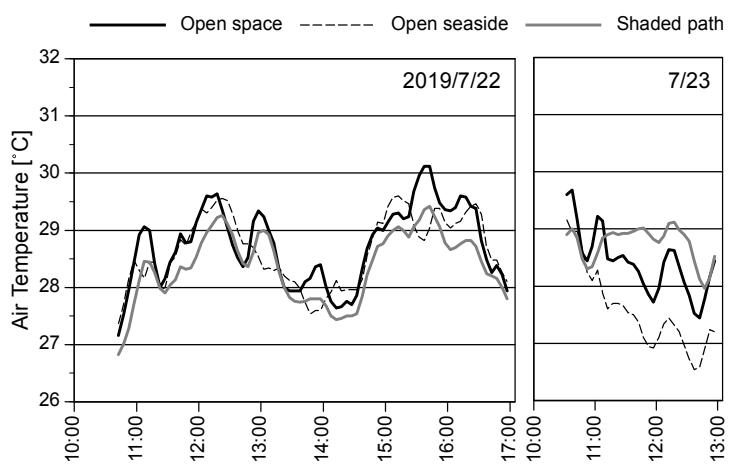

Fig. 9 Changes in air temperature at three representative measurement points on July 22nd and 23rd, 2019

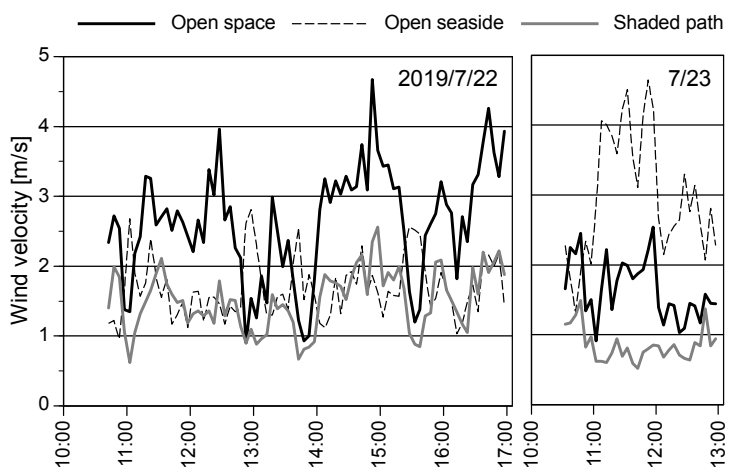

Fig. 10 Changes in wind velocities at three representative measurement points on July 22nd and 23rd, 2019 
concluded that the wind velocity at the shaded path (point-C) tended to be weaker than that at the open space and seaside because the group of wooden storehouses blocked the wind.

Figures 11-13 show the changes in short- and long-wave fluxes downward and upward at three representative measurement points on July 22nd and 23rd, 2019. Downward shortwave radiation at the open space (point-A) recorded a maximum value of $1090.6 \mathrm{~W} / \mathrm{m}^{2}$ at $12: 15$ on July $22 \mathrm{nd}$, and the average value during the measurement period was $657.0 \mathrm{~W} / \mathrm{m}^{2}$. From 13:05 to 14:10, downward short-wave radiation fluxes were less than $400 \mathrm{~W} / \mathrm{m}^{2}$ due to cloudiness. Meanwhile, upward

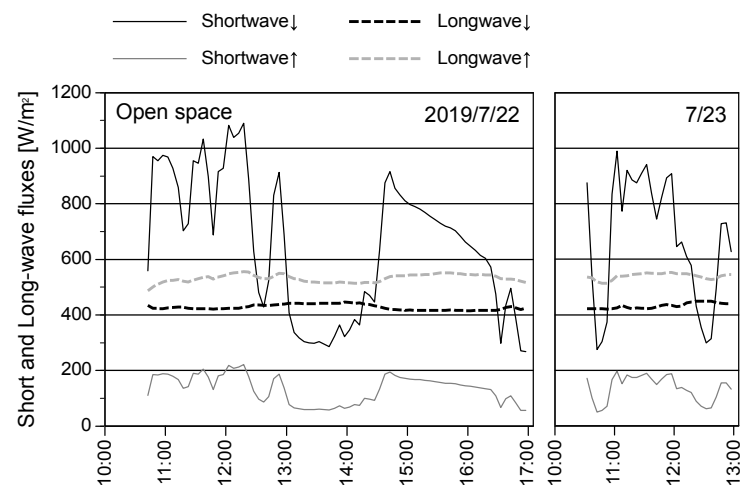

Fig. 11 Changes in short- and long-wave fluxes downward and upward at the open space (point-A)

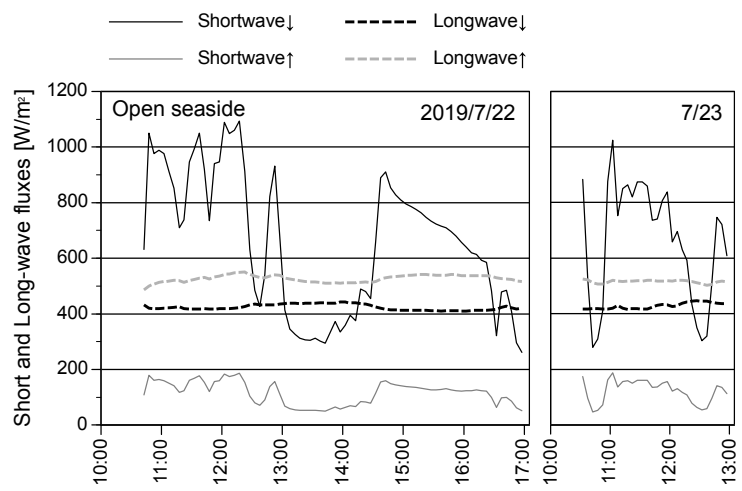

Fig. 12 Changes in short- and long-wave fluxes downward and upward at the open seaside (point-B)

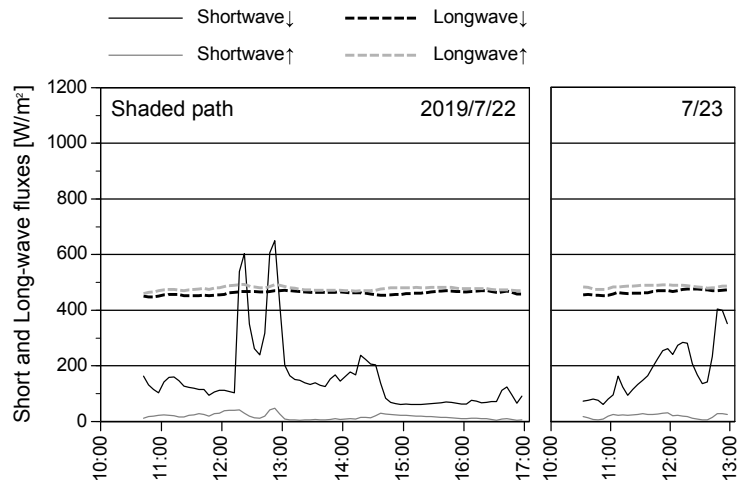

Fig. 13 Changes in short- and long-wave fluxes downward and upward at the shaded path (point-C) short-wave radiation reflected by the ground surface fluctuated below approximately $200 \mathrm{~W} / \mathrm{m}^{2}$. The mean values of downward longwave radiation from the sky and upward longwave radiation from the ground surface were 428.8 and $534.2 \mathrm{~W} / \mathrm{m}^{2}$, respectively. The changes in short- and long-wave radiation fluxes at the open seaside (point-B) were almost the same as those at the open space (point-A). The changes in short- and long-wave radiation fluxes at the shaded path in the group of wooden storehouses (point-C) differed significantly from those at the open space (point-A) and seaside (point-B). In particular, the values of shortwave radiation fluxes, both downward and upward, were small compared to the open space (point-A) and seaside (point-B). A maximum downward short-wave radiation of $650.2 \mathrm{~W} / \mathrm{m}^{2}$ was recorded at 12:50 on July $22 \mathrm{nd}$, and the average value during the measurement period was $162.5 \mathrm{~W} / \mathrm{m}^{2}$. From $12: 15$ to $14: 30$ on July 22nd and from 12:15 to 12:55 on July 23rd, direct solar radiation was irradiated measuring point- $\mathrm{C}$ between storehouses but diffuse solar radiation was mostly blocked by the storehouses; thus, the downward shortwave radiation at the shaded path (point-C) was approximately $50 \%$ of the value at the open space (point-A). The upward short-wave radiation reflected by the surface of the lower hemisphere fluctuated at less than $50 \mathrm{~W} / \mathrm{m}^{2}$ and the average value during the measurement period was $17.4 \mathrm{~W} / \mathrm{m}^{2}$. The average of the downward long-wave radiation from the upper hemisphere including the sky at the shaded path (point-C) was $462.7 \mathrm{~W} /$ $\mathrm{m}^{2}$, which was $33.9 \mathrm{~W} / \mathrm{m}^{2}$ larger than that at the open space (point-A). Meanwhile, the average of the upward long-wave radiation from the lower hemisphere including the ground surface was $479.1 \mathrm{~W} / \mathrm{m}^{2}$, which was $55.1 \mathrm{~W} / \mathrm{m}^{2}$ smaller than that at the open space (point-A).

Figure 14 shows changes in downward UV Index on a horizontal plane at three representative measurement points on July 22nd and 23rd, 2019. The changes of UV Index at the open space (point-A) and seaside (point-B) were almost the same, but the UV Index at

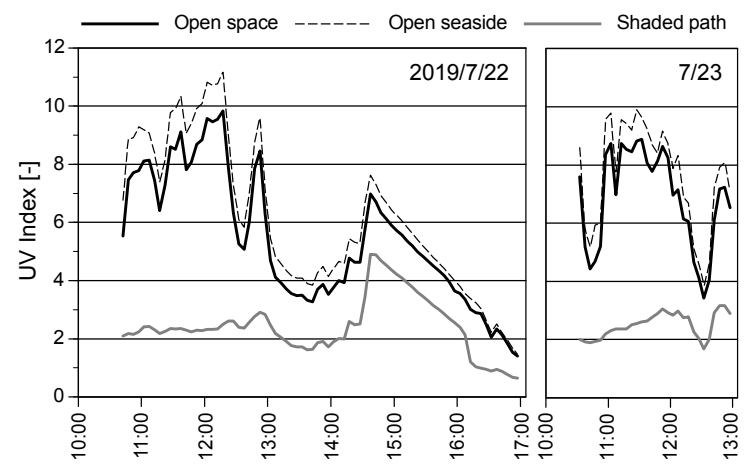

Fig. 14 Changes in UV Index at three representative measurement points on July 22nd and 23rd, 2019 
the open seaside (point-B) was slightly larger than that at the open space (point-A). The maximum UV Index values at the open space (point-A) and seaside (pointB) were 9.8 and 11.2 , respectively at $12: 15$ on July 22nd. According to WHO et al. (2002), these values were evaluated as "very high" and "extreme" UV radiation exposure, and the environment required extra protection against UV radiation. At the shaded path in the group of storehouses (point-C), the UV Index exceeded 3 from 14:30 to $15: 40$ on July 22nd, which is "moderate" UV radiation exposure. Except during this period, the UV Index was less than 3 at the shaded path, which was evaluated as "low" UV radiation exposure with no UV protection required according to WHO et al. (2002). The average values of UV Index at the open space, seaside and shaded path during the measurement period were 5.8, 6.6 and 2.4, respectively.

\section{Discussion}

During the observation in the daytime on a sunny summer day, the westerly wind was blowing in the sky and two patterns of the wind were observed in the northern part of the settlement, including the group of wooden storehouses. The wind direction in the northern part of the settlement had a different trend than that in the sky. The wind directions in Waniura settlement are affected by the topography when the wind in the sky blows in different directions from the valley line in the settlement.

On July 22nd, 2019, there was not enough sunshine in the morning for a sea breeze to develop. It is possible that the southeast wind blew in the northern part of Waniura settlement due to the blowing back of westerly wind to the opposite direction on the east slope of the settlement. Focusing on the temperature distribution at that time, a relatively high-temperature area was formed in the sunny open space, the drying place called "Be-Doko", and a relatively low-temperature area was formed in the shaded group of wooden storehouses. However, on July 23rd, 2019, there was enough sunshine in the morning for a weak sea breeze to develop. It is possible that the relatively low air temperature area formed near the harbour was a result of the cooling effect of the sea breeze. Focusing on the air temperature distribution at that time, it is likely that the relatively low air temperature area was formed in the airy open space.

The results of microclimate observations and measurements at representative points showed a trend of decreasing wind velocity in the group of wooden storehouses. However, the wind reducing effect tended to differ between the eastern and western area of the group of wooden storehouses, depending on the wind direction in the area near the harbour. The wind was calm or weak at the observation point in the western area of the group of wooden storehouses because the storehouses located in the north-south direction along the river block the southeast wind and the storehouses located in the east-west direction toward the harbour block the north wind, such as the weak sea breeze. The wind reducing effect against the north wind is also relatively clear in the eastern area of the group of wooden storehouses because the storehouses located in the east-west direction toward the harbour and the open space block the wind. In contrast, the southeast wind blows into the centre of the eastern area of the group of wooden storehouses along the arrangement of wooden storehouses. The layout of storehouses affects the wind environment of the group of wooden storehouses and the wind reducing effect appears when the wind blows from the direction orthogonal to the parallel storehouses.

In light of the results of the above study, we discuss the outdoor thermal indices formed at three representative measurement points. The MRT and the UTCI were calculated by climatic parameters measured at each representative measurement point. Figure 15 shows the changes in MRT at three measurement points on July 22nd and 23rd, 2019. There was little difference in the MRT between the open space (point-A) and the open seaside (point-B). The average values of MRT during the measurement period ware 57.6 and $56.1{ }^{\circ} \mathrm{C}$ at the open space (point-A) and the open seaside (pointB), respectively. In contrast, the average of MRT at the shaded path in the group of wooden storehouses (pointC) was $37.6^{\circ} \mathrm{C}$, which was approximately $20^{\circ} \mathrm{C}$ cooler on average than the open space (point-A) and open seaside (point-B). It was found that the blocking of solar radiation by the group of storehouses improved the radiant environment and cooled radiant temperature at the shaded path in the summer daytime.

Figure 16 shows the relation between global solar radiation and MRT reduction at the open seaside (pointB) and shaded path in the group of wooden storehouses (point-C). Global solar radiation was measured at the open space (point-A), which was open to the sky. MRT reductions at the open seaside (point-B) and shaded

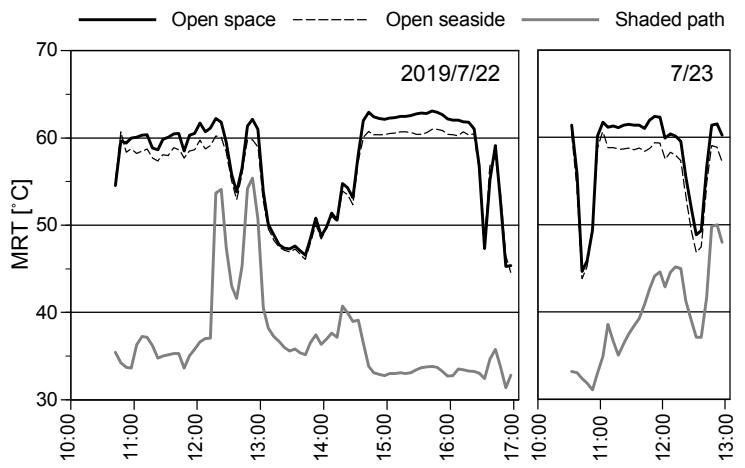

Fig. 15 Changes in MRT at three representative measurement points on July 22nd and 23rd, 2019 
path (point-C) indicate the difference from the MRT at the open space (point-A). Focusing on the regression line, the MRT reduction at the open seaside (point-B) was independent of global solar radiation. This means that MRTs at the open space (point-A) and seaside (point-B) were almost equal. In contrast, the MRT reduction at the shaded path in the group of wooden storehouses (point-C) increased with increasing global solar radiation. According to the regression line, at the shaded path (point-C) on the global solar radiation of $1,000 \mathrm{~W} / \mathrm{m}^{2}$, the MRT reduction was $-25.7{ }^{\circ} \mathrm{C}$. The reason the MRT at the shaded path dropped significantly was that storehouses built close to each other blocked the solar radiation on the shaded path significantly. Furthermore, less solar radiation on the shaded path might contribute to maintaining low surface temperatures of the pathway and the storehouses.

Figure 17 shows the changes in UTCI at three measurement points on July 22nd and 23rd, 2019. On July 22nd, UTCI were relatively high at the open space (point-A) and the open seaside (point-B), and relatively low at the shaded path in the group of wooden storehouses (point-C), except between 12:15 to 14:00, when solar radiation reached measurement point $\mathrm{C}$ through

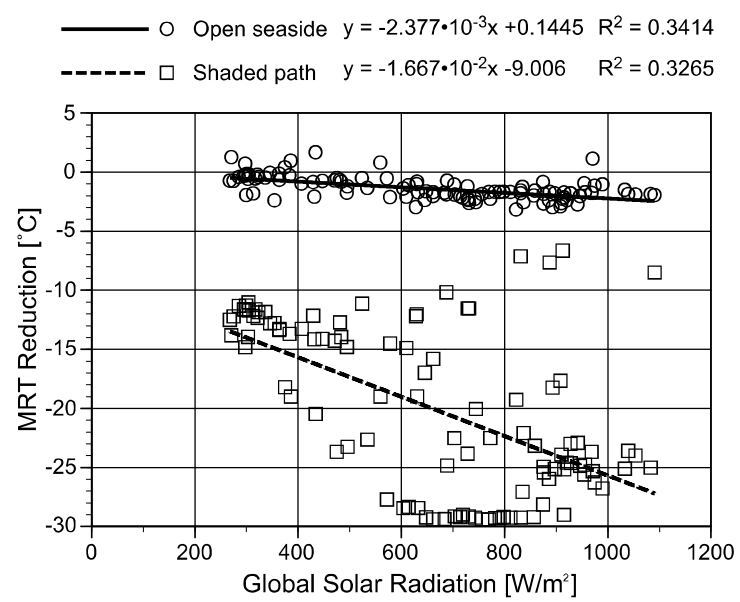

Fig. 16 Relation between global solar radiation and MRT reduction

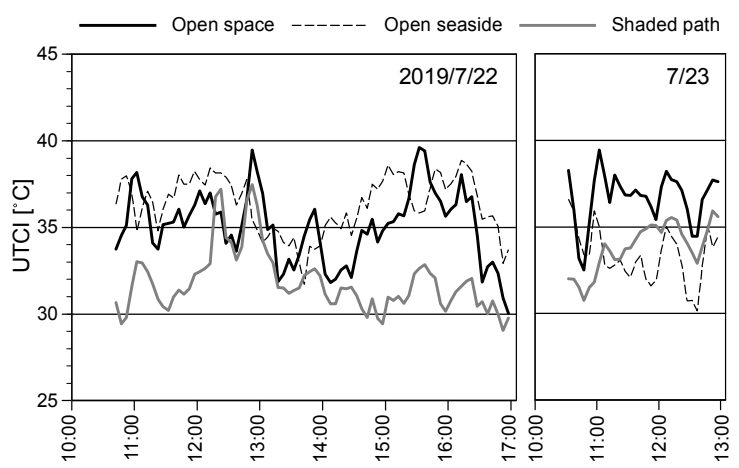

Fig. 17 Changes in UTCI at three representative measurement points on July 22nd and 23rd, 2019 the storehouses. Due to the blowing southeast wind, the cooling effect was clearly observed when the path between storehouses was shaded. The UTCI at the shaded path between storehouses (point-C) in this period was $4.1^{\circ} \mathrm{C}$ lower than that at the open space (point-A) on average. According to the UTCI Assessment Scale, the thermal environment at the open space (point-A) and the open seaside (point-B) were assessed to be "strong heat stress" (UTCI from +32 to $+38^{\circ} \mathrm{C}$ ) or "very strong heat stress" (UTCI from +38 to $+46^{\circ} \mathrm{C}$ ). When the wind blew, the thermal environment at the shaded path in the group of wooden storehouses (point-C) was assessed to be "moderate heat stress" (UTCI from +26 to $+32{ }^{\circ} \mathrm{C}$ ). On July 23rd, UTCI were relatively high at the open space (point-A) and relatively low at the open seaside (point-B) and the shaded path in the group of wooden storehouses (point-C). The cooling effect of the group of storehouses was not clear because the wind was weak at measurement point $\mathrm{C}$ on this day. Meanwhile, the cooling effect of the sea breeze was clearly observed at the open seaside (point-B).

Figure 18 shows the relation between global solar radiation and UTCI reduction. Global solar radiation was measured at the open space (point-A), which was open to the sky. UTCI reduction at the open seaside (point-B) and shaded path in the group of wooden storehouses (point-C) indicate the difference from UTCI at the open space (point-A). Focusing on the regression line, the UTCI reduction at the open seaside (point-B) was independent of global solar radiation and the average of UTCI reduction was $-0.1^{\circ} \mathrm{C}$. In contrast, the UTCI reduction at the shaded path (point-C) increased with increasing global solar radiation. At the shaded path on $1,000 \mathrm{~W} / \mathrm{m}^{2}$ of global solar radiation, the UTCI reduction was $-4.4^{\circ} \mathrm{C}$. This result emphasizes the importance of providing shade using buildings or other means and directing wind into those spaces to improve the outdoor thermal environment.

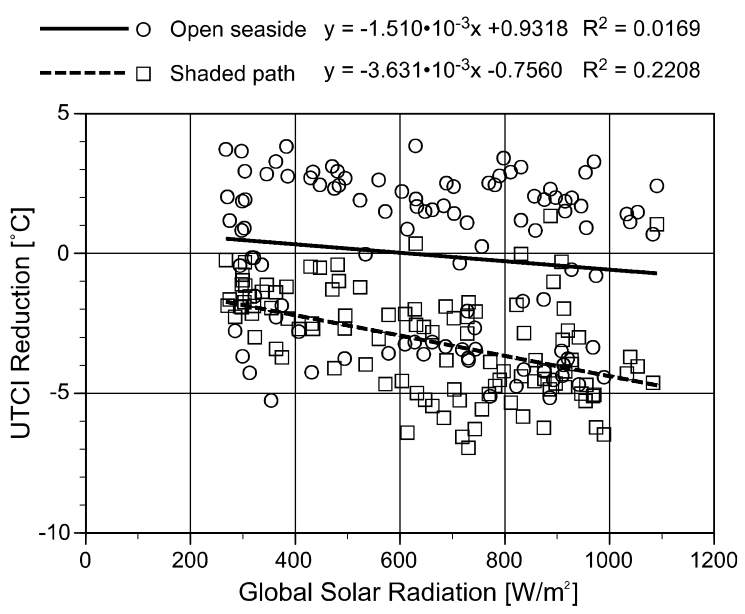

Fig. 18 Relation between global solar radiation and UTCI reduction 
Next, we discuss the UV intensities at three representative measurement points. Figure 19 shows the relation between global solar radiation and UV Index reduction at the open seaside (point-B) and shaded path in the group of wooden storehouses (point-C). Global solar radiation was measured at the open space (pointA), which was open to the sky. UV Index reductions at the open seaside and shaded path indicate the difference from UV Index at the open space (point-A). The UV Index reduction at the open seaside (point-B) was distributed between 0 and 2 . This result shows that the UV Index at the open seaside (point-B) was larger than that at the open space (point-A), which can be explained by the larger SVF at the open seaside. In contrast, UV Index reduction at the shaded path (point-C) increased with increasing global solar radiation. At the shaded path on $1,000 \mathrm{~W} / \mathrm{m}^{2}$ of global solar radiation, the UV Index reduction was -5.4 according to the regression line. This large UV Index reduction at the shaded path can be explained by the storehouses being built in close to each other, thus blocking most direct and diffuse components of UV radiation.

To add to the above results, it has become clear that a heat island appears in the centre of the settlement with a population of about 200 people in the daytime on a clear summer day. In contrast, the heat island did not appear in the group of wooden storehouses, despite the dense construction of storehouses. This is probably because the storehouse is a low-rise wooden building with a low heat capacity and because there is no energy consumption or waste heat there.

According to the above results, it is evident that a cooling effect from the group of storehouses on the radiant environment, sensible temperature and UV environment appears in the summer daytime. Based on the results of the field observations, it has been empirically shown that an effective environmental design method for mitigating the thermal environment in the summer daytime can be done by composing a group of

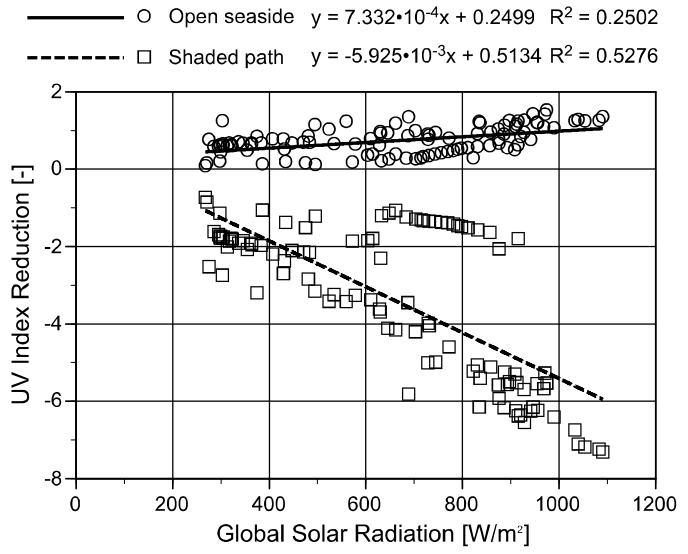

Fig. 19 Relation between global solar radiation and UV Index reduction low-rise wooden buildings and taking into account their cross ventilation.

\section{Conclusions}

This study focused on the outdoor thermal environment of the traditional settlement Waniura with a group of wooden storehouses in Tsushima Island, Japan. The microclimate observations in the settlement and the heat parameter measurements, including UV intensities at three representative points, were carried out in the summer of 2019. The layout of storehouses affected the wind environment in and around the group of wooden storehouses. In particular, the wind reducing effect appears when the wind blows from the direction orthogonal to the parallel storehouses. According to the regression analysis based on the measurement data, at the shaded path in the group of wooden storehouses on $1,000 \mathrm{~W} / \mathrm{m}^{2}$ of global solar radiation, the MRT reduction was $-25.7^{\circ} \mathrm{C}$, the UTCI reduction was $-4.4^{\circ} \mathrm{C}$, and UV Index reduction was -5.4 . These results clearly emphasized that the radiant environment was improved, the UTCI was lowered, and the UV environment was improved in the group of wooden storehouses during the summer daytime. On a clear summer day, a heat island appeared in the centre of the settlement with a population of approximately 200 people in the daytime. In contrast, a heat island was not identified in the group of wooden storehouses, despite the dense construction of storehouses. Consequently, constructing a group of low-rise wooden buildings considering cross ventilation might be an effective environmental design methods for mitigating the thermal environment during the daytime in summer.

Based on the results at a representative point, it is evident that the cooling effects on the radiant environment, thermal environment and UV environment appears at the shaded path in the group of storehouses. As a next step, it is necessary to conduct the multi-point observations in and around the area of the group of wooden storehouses. And the cooling effects of the group of storehouses are expected to affect the indoor thermal environment of the storehouse, although this is a subject for further study. In this study, we reported the results of summer observations, although it is needed that observations in other seasons will also be conducted.

\section{Acknowledgements}

We thank Risa Ito, Miyako Urakawa, Hinako Mizuhata, Yuya Saeki, and Fumiya Hayakawa for conducting observations and measurements for this study. This work was supported by JSPS KAKENHI Grant Number JP16H3013. 


\section{References}

Bröde, P., Fiala, D., Błażejczyk, K., Holmér, I., Jendritzky, G., Kampmann, B., Tinz, B. and Havenith, G. (2012) Deriving the operational procedure for the Universal Thermal Climate Index (UTCI). International Journal of Biometeorology, 56: 481-494.

Chu, Y., Hsu, M., Hsieh, C. (2017) An example of ecological wisdom in historical settlement: The wind environment of Huazhai Village in Taiwan. Journal of Asian Architecture and Building Engineering 16(3): 463-470.

Hashimoto, T., Kobayashi, H., Sato, N., Kon, K., Kurihara, K. (2019) Local climatological study on layout of stone roof storehouses in Tsushima Island, Japan. Journal of Human and Living Environment 26(2): 101-112. [in Japanese]

Höppe, P. (1999) The physiological equivalent temperature - a universal index for the biometeorological assessment of the thermal environment, International Journal of Biometeorology 43 (2): 71-75.

Horikoshi, T., Tsuchikawa, T., Kobayashi, Y., (19901991) Changes of landscape and dwellings with windbreaks caused by urbanization in Central Japan. Energy and Buildings 15: 305-313.

Horikoshi, H., Tsuchikawa, T., Kobayashi, Y., Miwa, E., Kurazumi, Y., Hirayama, K. (1990) The effective radiation area and angle factor between man and a rectangular plane near him, ASHRAE Transactions 96: 60-66.

Jendritzky, G., de Dear, R., Havenith, G. (2012) UTCI - Why another thermal index?, International Journal of Biometeorology 56 (3): 421-428.

Kobayashi, H., Ando, K., Kurosaka, T., Hama, S., You, H., Kamatoko, M. (2007) The character of the wooden construction systems of storehouse "Koya" in Tsushima Is. Nagasaki. AIJ Journal of Technology and Design 13(26): 699-704. [in Japanese]

Nagano, K., Horikoshi, T. (2011) New index indicating the universal and separate effects on human comfort under outdoor and non-uniform thermal conditions,
Energy and Buildings 43 (7): 1694-1701.

Natsume, M. (2019) Wind condition analysis of Japanese rural landscapes in the 19th century: A case study of Kichijoji village in Musashino upland. International Journal of Geo-Information 8(9), 396: 1-11.

Park, S., Tuller, S. E. (2011) Human body area factors for radiation exchange analysis: standing and walking postures, International journal of biometeorology 55(5): 695-709.

Pickup, J., de Dear, R. (2000) An Outdoor Thermal Comfort Index (OUT-SET*) - Part I - the Model and its Assumptions, Biometeorology and Urban Climatology at the Turn of the Millennium, WCASP 50, WMO/TD 1026: 279-283.

Sekiguti, T. (1950) Rural houses and prevailing winds: Local climatological study of the Akaho Fan, KamiIna, Nagano Pref. No.3. Papers in Meteorology and Geophysics 1(1): 67-76.

Tao, J., Chen, H., Xiao, D. (2017) Influences of the natural environment on traditional settlement patterns: A case study of Hakka traditional settlements in eastern Guangdong Province. Journal of Asian Architecture and Building Engineering 16(1): 9-14.

Watanabe, S., Horikoshi, T. (2012) Calculation of mean radiant temperature in outdoors based on measurements, Japanese Journal of Biometeorology 49(2): 49-59. [in Japanese]

Watanabe, S., Horikoshi, T., Ishii, J., Tomita, A. (2013) The measurement of the solar absorptance of the clothed human body-The case of Japanese, collegeaged male subjects. Building and environment 59: 492-500.

World Health Organization (WHO), World Meteorological Organization(WMO), United Nations Environment Programme (UNEP), and International Commission on Non-Ionizing Radiation Protection (ICNIRP) (2002) Global solar UV index, a practical guide.

Yaglou, P., Minard, D. (1957) Control of heat casualties at military training centers, A. M. A. Archives of Industrial Health 16: 302-316. 